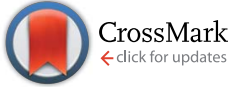

Cite this: Chem. Sci., 2015, 6, 152

Received 6th August 2014

Accepted 16th September 2014

DOI: $10.1039 / c 4 s c 02380 c$

www.rsc.org/chemicalscience

\section{Extremely strong tubular stacking of aromatic oligoamide macrocycles $\uparrow$}

\author{
Mark A. Kline, $\dot{t}^{a}$ Xiaoxi Wei,,$_{+}^{a}$ Ian J. Horner, ${ }^{a}$ Rui Liu, ${ }^{a}$ Shuang Chen, ${ }^{b}$ Si Chen, ${ }^{c}$ \\ Ka Yi Yung, ${ }^{a}$ Kazuhiro Yamato, ${ }^{a}$ Zhonghou Cai, ${ }^{c}$ Frank V. Bright, ${ }^{a}$ Xiao Cheng Zeng ${ }^{b}$ \\ and Bing Gong ${ }^{\star a d}$
}

As the third-generation rigid macrocycles evolved from progenitor 1, cyclic aromatic oligoamides 3, with a backbone of reduced constraint, exhibit extremely strong stacking with an astoundingly high affinity (estimated lower limit of $K_{\text {dimer }}>10^{13} \mathrm{M}^{-1}$ in $\mathrm{CHCl}_{3}$ ), which leads to dispersed tubular stacks that undergo further assembly in solution. Computational study reveals a very large binding energy $(-49.77$ kcal $\mathrm{mol}^{-1}$ ) and indicates highly cooperative local dipole interactions that account for the observed strength and directionality for the stacking of 3 . In the solid-state, X-ray diffraction (XRD) confirms that the aggregation of 3 results in well-aligned tubular stacks. The persistent tubular assemblies of 3 , with their non-deformable sub-nm pore, are expected to possess many interesting functions. One such function, transmembrane ion transport, is observed for 3 .

\section{Introduction}

Tubular structures, with their cylindrical shapes, defined outer and inner surfaces, and internal pores, provide versatile structural modules for constructing functional structures. ${ }^{1,2}$ Nanopores with precisely defined diameters of less than $2 \mathrm{~nm}$, such as those of carbon nanotubes (CNTs), exhibit many fascinating properties. ${ }^{3,4}$ Compared with carbon nanotubes, organic nanotubes ${ }^{5}$ have unique advantages such as ready functionalization, versatile compatibility, and modular assembly. Among known strategies, ${ }^{2,5,6}$ the superposition of cyclic building blocks ${ }^{5 a, e-g, 7}$ represents an approach that combines the ready modifiability of small molecules and the power of self-assembly, leading to nanotubes with structural and functional tunability. However, the alignment of cyclic molecules based on non-covalent forces is often impeded by limitations such as the poor directionality of $\pi-\pi$ stacking and/or the limited strength of hydrogenbonding, especially in polar media, which frequently lead to undesired outcomes upon even a slight structural modification on an otherwise promising building block.

\footnotetext{
${ }^{a}$ Department of Chemistry, the State University of New York at Buffalo, Buffalo, New York, USA 14260.E-mail: bgong@buffalo.edu; Web: http://www.chemistry.buffalo. edu/people/faculty/gong/

${ }^{b}$ Department of Chemistry, University of Nebraska-Lincoln, Lincoln, Nebraska 68588, USA

${ }^{c} X$-ray Science Division, Argonne National Laboratory, 9700 South Cass Avenue, Argonne, IL 60439, USA

${ }^{d}$ College of Chemistry, Beijing Normal University, Beijing 100875, China

$\dagger$ Electronic supplementary information (ESI) available. See DOI: $10.1039 / \mathrm{c} 4 \mathrm{sc} 02380 \mathrm{c}$

$\ddagger$ These authors contributed equally to this work.
}

Given the many remarkable functions exhibited by or expected of non-deformable nanopores, ${ }^{3,4}$ organic nanotubes resulted from the stacking of rigid macrocycles, which contain non-collapsible inner pores, is especially attractive. ${ }^{8}$ While many rigid macrocycles such as those with $\pi$-conjugated ${ }^{9,10}$ and other backbones, ${ }^{11-15}$ along with tubular stacks of some of these macrocycles in the solid and liquid crystalline phases, ${ }^{5 d-f, 7}$ are known, self-assembling nanotubes that stably exist in solution are rare. The availability of stable nanotubular assemblies should greatly advance the development of systems with properties typically associated with biological structures. Achieving this objective requires the strong, directional stacking of cyclic building blocks.

Over the years, we have developed several different classes of rigid macrocycles containing non-deformable internal cavities. ${ }^{16}$ The first generation of such molecules are aromatic oligoamide macrocycles $1,{ }^{14 a}$ which were found to form efficiently in one pot while we attempted to prepare folding aromatic oligoamides ${ }^{17,18}$ and polyamides ${ }^{19}$ having similar backbones. The one-pot macrocyclization we found has led to rigid macrocycles containing internal cavities of 5 to $30 \AA$ across. ${ }^{16,20}$ The benzene residues of macrocycles $\mathbf{1}$ are connected via amide groups engaging in highly favourable three-centre intramolecular hydrogen-bonding interaction ${ }^{21}$ that constrains the macrocyclic backbones. With fully constrained, non-deformable backbones, macrocycles 1 were observed to strongly aggregate in solution and form tubular stacks in the solid state. ${ }^{22}$

To better control the alignment of these molecules, amide side chains are attached to $\mathbf{1}$, which led to the second-generation macrocycles 2 . Being flanked by alkoxy side chains, the amide side chains of $\mathbf{2}$ are perpendicular to the benzene rings to 
which they are attached and should thus be predisposed to intermolecular $\mathrm{H}$-bonding that enforces the macrocycles to stack on top of one another into a tubular stack. Surprisingly, studies using multiple analytical techniques suggested that macrocycles 2 underwent insignificant aggregation. ${ }^{23}$ It seemed that the amide side chains of 2 not only failed to engage in intermolecular H-bonding, but also abolished the otherwise strong aggregation of $\mathbf{1}$.

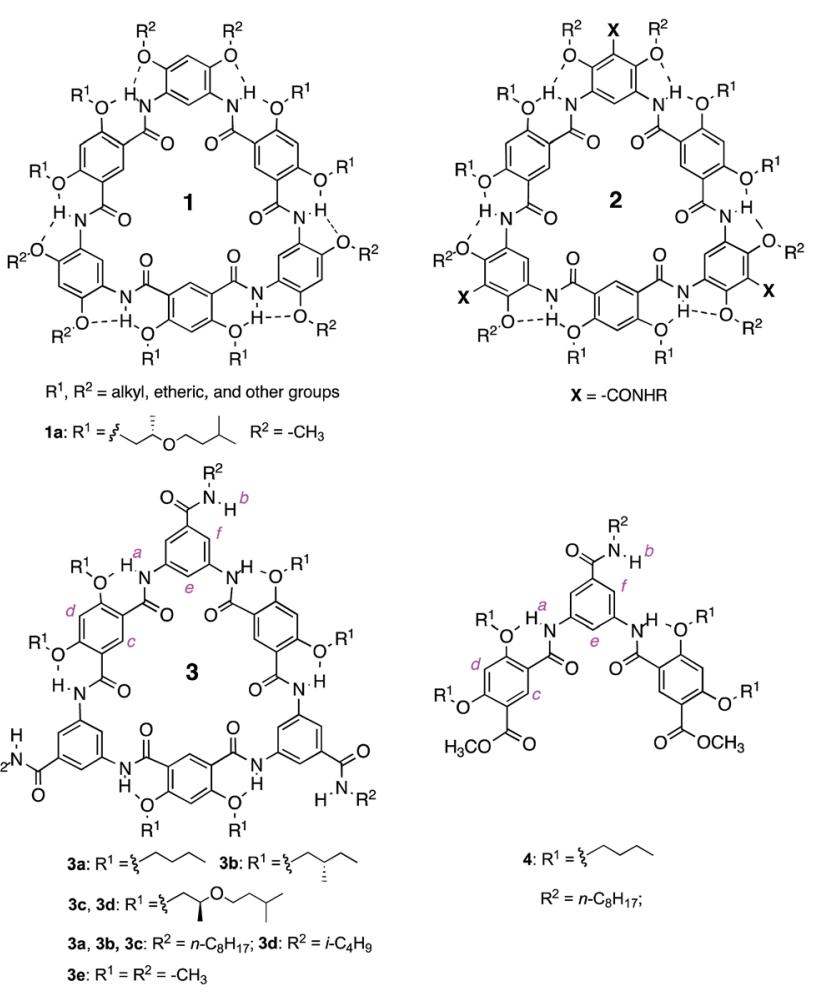

The unexpected behavior of macrocycles 2 may be due to steric crowdedness that hampers side-chain H-bonding and backbone $\pi-\pi$ stacking. Such a besetment could be evaded by removing the alkoxy groups flanking the amide side chains of $\mathbf{2}$, which leads to 3 , our third-generation aromatic oligoamide macrocycles. ${ }^{24}$ Herein, we report the unusually strong tubular stacking of 3. It was found that, in solution, macrocycles 3 underwent aggregation that was mediated by their backbones and weakened by polar solvents. The self-association of 3 is extremely strong, with a strength that is, to the best of our knowledge, unprecedentedly high. The strong association of 3 results in individually dissolved columnar stacks that dominate at low concentrations and further pack at elevated concentrations. X-ray diffraction (XRD) revealed the columnar stacks of 3 and their hexagonal packing in the solid state. Consistent with their reliable tubular self-assembly, macrocycles $\mathbf{3}$ were found to mediate efficient transmembrane transport of ions.

\section{Results and discussion}

\section{Backbone-mediated aggregation}

The aggregation of macrocycles 3a-d was first indicated by their ${ }^{1} \mathrm{H}$ NMR spectra. In $\mathrm{CDCl}_{3}$, no signals could be found in the

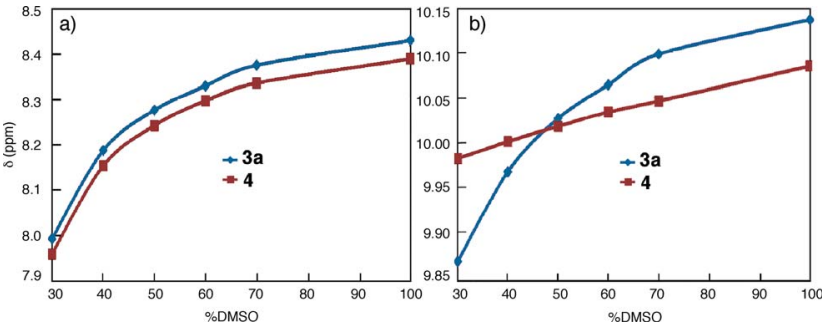

Fig. 1 Plots of the chemical shifts of (a) protons $b$ and (b) protons $a$ of 3a (1 mM, blue) and 4 ( $1 \mathrm{mM}$, red), against volume percent DMSO- $\mathrm{d}_{6}$ in $\mathrm{CDCl}_{3}$.

amide and aromatic region. The only peaks observed are those from $0.5 \mathrm{ppm}$ to $1.8 \mathrm{ppm}$, which belong to the terminal alkyl groups of the side chains (Fig. S1 in the ESI†). This observation suggests that 3a-d undergo decreased molecular motion due to aggregation involving their oligoamide backbones. In DMF- $\mathrm{d}_{7}$ or DMSO- $\mathrm{d}_{6}$, the ${ }^{1} \mathrm{H}$ NMR spectra of 3a-d contain well dispersed signals (Fig. S2 $\dagger$ ), suggesting that the aggregation of these molecules is interrupted in polar solvents.

To gain additional insights, the ${ }^{1} \mathrm{H}$ NMR spectra of $3 \mathbf{a}$ were recorded in $\mathrm{CDCl}_{3}(1 \mathrm{mM})$ containing incremental proportions of DMSO- $\mathrm{d}_{6}$. The signals of amide and aromatic protons only become obvious in solvents with $30 \%$ or more DMSO- $_{6}$ (Fig. S3 $\uparrow$ ). The same trend was observed with increasing ratios of DMF-d 7 (Fig. S4†). In comparison to macrocycles 1 that gave well dispersed ${ }^{1} \mathrm{H}$ NMR signals with as few as $5 \%$ DMSO- $\mathrm{d}_{6}$ or DMF- $\mathrm{d}_{7}$ in $\mathrm{CDCl}_{3},{ }^{14 a}$ the aggregation of $3 \mathrm{a}$, as indicated by the effect of DMF or DMSO, is much stronger. Plotting the chemical shifts of the amide protons of 3a and those of $\mathbf{4}$ against DMSO$\mathrm{d}_{6}$ contents indicates that amide protons $b$ of $3 \mathbf{a}$ and 4 follow the same trend with changing solvent polarity (Fig. 1a). This observation suggests that the side-chain $\mathrm{NH}$ groups of 3a, like that of the molecularly dissolved 4 (Fig. S5 $\dagger$ ), are exposed to solvent. In contrast, with increasing ratios of DMSO- $\mathrm{d}_{6}$, the downfield shifts of amide protons $a$ are non-linear for $\mathbf{3 a}$, and linear for trimer 4 (Fig. 1b). The different behavior of protons $a$ of 3a and 4 can be explained by the stacking of $3 \mathbf{a}$ in $\mathrm{CDCl}_{3}$, which shields the oligoamide backbone from solvent molecules. Increasing solvent polarity weakens and eventually breaks up the aggregates, which exposes individual molecules, and hence protons $a$, of $3 \mathbf{a}$ to solvent molecules.
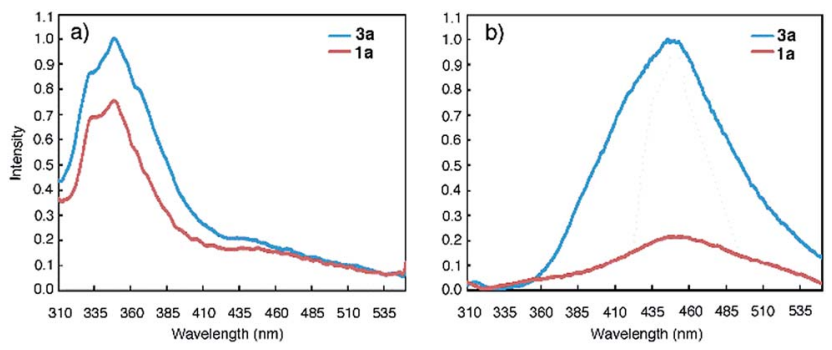

Fig. 2 Fluorescence spectra of 1a (red) and 3a (blue) in (a) DMF (1 $\mu \mathrm{M})$ and, (b) $\mathrm{CHCl}_{3}(1 \mu \mathrm{M})$ using an excitation wavelength of $282 \mathrm{~nm}$. 
Experiments based on diffusion-ordered spectroscopy (DOSY) in $\mathrm{CDCl}_{3}$ containing $40 \%$ DMF- $\mathrm{d}_{7}$ clearly demonstrated the aggregation of $3 \mathbf{a}$ and the lack of aggregation in pure DMF$\mathrm{d}_{7}$ (Fig. S6†). Dynamic light scattering (DLS) was also used to compare the aggregation of 3a and 1a. In DMF, neither 3a nor 1a formed any noticeable aggregate. In contrast, aggregates of 3a $(1 \mathrm{mM})$, with an average hydrodynamic diameter $[(2.6 \pm 0.6)$ $\left.\times 10^{4} \mathrm{~nm}\right]$ that is much larger than that $[(250 \pm 18) \mathrm{nm}]$ of the aggregates formed by $1 \mathrm{a}$ were observed in chloroform. The DLS results corroborate those from DOSY and ${ }^{1} \mathrm{H}$ NMR, confirming that the aggregation of $\mathbf{3 a}$ is much stronger than that of $\mathbf{1 a}$.

\section{Ground-state aggregation}

Macrocycles 1a and 3a were then examined at $1 \mu \mathrm{M}$, a concentration that is three orders of magnitude lower than those used for NMR and DLS studies, with fluorescence spectroscopy. In DMF, emission bands centred at $350 \mathrm{~nm}$, which can be ascribed to molecularly dissolved monomers, are observed (Fig. 2a). In $\mathrm{CHCl}_{3}$, macrocycles 1a and 3a display broad, red-shifted bands at $450 \mathrm{~nm}$ (Fig. 2b). The $450 \mathrm{~nm}$ bands are reminiscent of excimer fluorescence typical of $\pi$-stacked aromatic rings ${ }^{25}$ that exist in the ground state (i.e., due to aggregation) and give "excimer-like" emission. ${ }^{26}$ Consistent with the ground-state association of 3a, monitoring the emission bands of 3a (125 nM and $0.1 \mathrm{pM}$ in $\mathrm{CHCl}_{3}$ ) at $350 \mathrm{~nm}$ and $450 \mathrm{~nm}$ revealed two different peaks at $260 \mathrm{~nm}$ and $280 \mathrm{~nm}$, respectively, in the excitation spectra (Fig. S7†).

Emission spectra collected at reduced concentrations in $\mathrm{CHCl}_{3}$ indicate that 3a remains aggregated down to $1 \mathrm{pM}$ and exists as monomers only at $0.1 \mathrm{pM}$ (Fig. 3a). Assuming that, at 1 $\mathrm{pM}$, macrocycle $\mathbf{3 a}$ is involved in a monomer-dimer equilibrium $^{10 b}$ with a $10 \%$ dissociation, a lower limit of $4.5 \times 10^{13}$ $\mathbf{M}^{-1}$ for the dimerization constant can be estimated, which suggests that 3a engages in remarkably strong association. In contrast, the fluorescence spectra of 1 a recorded below $100 \mathrm{nM}$ contain emission bands at both $350 \mathrm{~nm}$ and $450 \mathrm{~nm}$; at $10 \mathrm{nM}$, the emission band at $450 \mathrm{~nm}$ greatly weakens while the one around $350 \mathrm{~nm}$ becomes dominant (Fig. 3b). These observations demonstrate that the aggregation of $\mathbf{3 a}$ is several orders of magnitude stronger than that of 1a.

The effect of solvent polarity on the aggregation of $\mathbf{3 a}$ and $1 \mathrm{a}$ $(1 \mu \mathrm{M})$ was revealed by plotting $E_{450} / E_{350}$, the ratios of normalized fluorescence emissions at $450 \mathrm{~nm}$ and $350 \mathrm{~nm}$, as a function of volume percent $\mathrm{CHCl}_{3}$ in DMF (Fig. S8 and Table S1 $\dagger$ ).
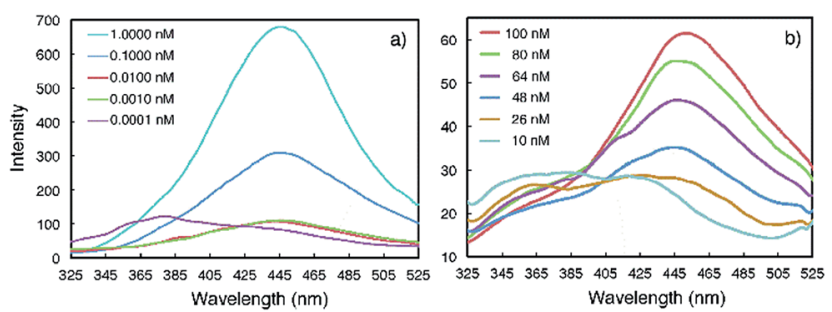

Fig. 3 Fluorescence spectra of (a) 3a and (b) 1a recorded at different concentrations in $\mathrm{CHCl}_{3}$ using an excitation wavelength of $282 \mathrm{~nm}$.
The $E_{450} / E_{350}$ ratio rises with increasing volume percent $\mathrm{CHCl}_{3}$ in DMF. In contrast, the intensity of the $450 \mathrm{~nm}$ band of $1 \mathrm{a}(1$ $\mu \mathrm{M})$ is much less prominent than that of $\mathbf{3 a}$. These observations confirm the high sensitivity of the aggregation of $3 a$, even at a very low concentration, to solvent polarity, which implies the involvement of a strong dipole-dipole factor in the self-association of this compound.

\section{Insights from computational study}

To gain insights into the strong self-association of 3 , ab initio computation was performed on a dimer consisting of two stacked molecules of model macrocycle 3e. The potential energy as a function of the relative stacking angle between two such macrocyclic units was calculated at the density-functional theory (DFT) level of M06-2X/6-31G(d), with the molecular structure being optimized at the DFT BLYP-D3/GTH level with inclusion of dispersion correction (see the ESI $\dagger$ ). It was found that the dimer with a stacking angle of $60.5^{\circ}$ gave the strongest binding, with a binding energy of $-49.77 \mathrm{kcal} \mathrm{mol}^{-1}$. In contrast, the dimer involving two "eclipsed" molecules, i.e., with a stacking angle of $0^{\circ}$, had a binding energy of $-24.42 \mathrm{kcal}$ $\mathrm{mol}^{-1}$. The drastically enhanced stability of the most stable dimer may be explained by the highly cooperative interaction of local dipoles. With a stacking angle of $60^{\circ}$, the two different types of benzene residues, one derived from the diacid monomer and the other derived from the diamine monomer, stack directly on top of each other and undergo favourable dipoledipole attraction. The highly cooperative action of six such pairs of benzene residues is most likely responsible for the observed strong association of $\mathbf{3 a}$.

\section{Time course of aggregation: a two-stage process}

The progress of the aggregation of $\mathbf{1 a}$ and $\mathbf{3 a}$ was monitored by following the intensity of the $450 \mathrm{~nm}$ band upon adding a solution of $3 \mathbf{a}$ or $\mathbf{1 a}$ in DMF into $\mathrm{CHCl}_{3}$. It was found that the rate of aggregation increased with increasing proportion of $\mathrm{CHCl}_{3}$ (Fig. S9†). Fig. 4 shows the time courses for the $450 \mathrm{~nm}$ band of $1 \mathrm{a}$ or $3 \mathrm{a}(1 \mu \mathrm{M})$ in $\mathrm{CHCl}_{3}$ and $\mathrm{DMF}(1 / 1, \mathrm{v} / \mathrm{v})$. The aggregation of 3a involves two stages: an initial rapid growth phase that lasts for about $37 \mathrm{~min}$, followed by a much slower growth phase (Fig. 4a, red). In the same solvent, the aggregation of 1a is negligible, with no obvious increase being observed for
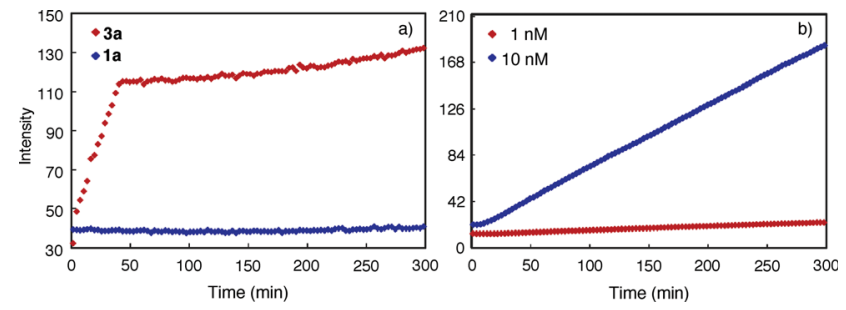

Fig. 4 Change of fluorescence intensity at $450 \mathrm{~nm}$ as a function of time. (a) Upon mixing 3a or 1a dissolved in $\mathrm{DMF}$ with $\mathrm{CHCl}_{3}$. The final concentration of $1 \mathrm{a}$ or $3 \mathrm{a}$ is $1 \mu \mathrm{M}$ and, (b) $3 a$ ( $10 \mathrm{nM}$ and $1 \mathrm{nM}$ ), in the mixed solvent of $\mathrm{CHCl}_{3}$ and DMF $(1 / 1, \mathrm{v} / \mathrm{v})$. The measurements were carried out using an excitation wavelength of $281 \mathrm{~nm}$. 
its $450 \mathrm{~nm}$ band (Fig. 4a, blue). Lowering the concentration of 3a decreased the rates of aggregation considerably (Fig. S10†) and, below certain concentration, resulted in the disappearance of the second growth phase, even at greatly increased $\mathrm{CHCl}_{3}$ content. For example, at $10 \mathrm{nM}$, macrocycle 3a, being aggregated as shown by its $450 \mathrm{~nm}$ band (Fig. S11†), gives one growth phase (Fig. 4b). At $1 \mathrm{pM}$ in the same solvent, macrocycle $3 \mathrm{a}$ exists mainly as monomers (Fig. S12 $\dagger$ ) and, consistent with the lack of aggregation, shows insignificant increase of emission at $450 \mathrm{~nm}$ (Fig. S13†).

The observed fluorescence emission and two-stage time course associated with the aggregation of $\mathbf{3 a}$ may be rationalized by a model that involves an initial (fast) assembling period during which the molecules of 3a undergo strong, backbonemediated stacking, followed by a second (slow) phase in which the columnar stacks of 3a further pack via the surface interactions between columns (Fig. $\mathrm{S} 14 \dagger$ ). The initial phase is fast because, when $\mathbf{3 a}$ starts to aggregate, the concentration of monomer is high and that of the columns is negligible. The packing of columns is slower because the concentration of the columns is much lower than the monomers and it takes more time for the columns to diffuse and then to achieve optimum surface contact. The sharp transition from the first to the second phase thus indicates a threshold beyond which the packing of columns becomes dominant. At low concentrations, the second growth phase is no longer observable because the macrocyclic molecules are not able to stack into columns with the length and/or concentration needed for further packing. This also suggests that at low but aggregating concentrations, individually dissolved columnar stacks dominate.

\section{Individually dissolved columns in solution}

The likely presence of dispersed stacks of $\mathbf{3 a}$ in $\mathrm{CHCl}_{3}$ was probed with steady-state fluorescence anisotropy at $25{ }^{\circ} \mathrm{C}$ (see the $\mathrm{ESI} \dagger$ ). At $10 \mathrm{nM}$, a concentration at which $3 \mathbf{a}$ remains fully aggregated as shown by its emission spectrum (Fig. S15 $\dagger$ ), the aggregate of $\mathbf{3 a}$, assumed to be a rotating "sphere", has a diameter of $3.0 \mathrm{~nm}$ that is surprisingly close to that of $\mathbf{3 a}$ with side chains included. A plausible explanation is that the revealed diameter reflects the rotation of dispersed stacks of $\mathbf{3 a}$ around their long axes. In solution, only the self-spin of the cylindrical stacks is detected because such spin is much faster than the tumbling of the stacks around directions perpendicular to their long axes. Based on the

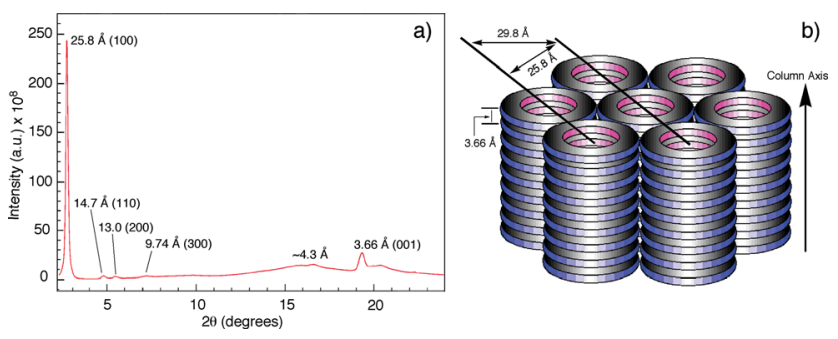

Fig. 5 (a) Diffractogram of the solid sample of 3a. (b) Schematic drawing of the columnar packing of $3 a$ and the hexagonal lattice. The hexagonal lattice parameter $a$ is $29.8 \AA$. data from fluorescence anisotropy and a refined model involving cylindrical stacks, the stacks of $3 \mathbf{a}$, at $10 \mathrm{nM}$, have an average of six macrocyclic molecules (see the ESI†).

\section{Columnar assembly in the solid state}

The columnar assembly of 3a was confirmed by XRD analysis on a solid sample prepared by drop-casting a solution in chloroform onto a glass plate. The obtained diffractogram contains a very intense peak at $25.8 \AA$ that overshadows other peaks (Fig. 5). The $25.8 \AA$ reflection and those at $14.7 \AA$, $13.0 \AA$, and $9.74 \AA$, with ratios of $d$-spacings being $1: 1 / \sqrt{3}: 1 / 2: 1 / \sqrt{7}$ (Fig. 5a), are typical of columnar stacks of disc-like molecules that further packed on a hexagonal $\left(\mathrm{col}_{\mathrm{h}}\right)$ lattice (Fig. $\left.5 \mathrm{~b}\right) .^{27}$ Based on the $25.8 \AA$ peak, the hexagonal lattice parameter $a$, i.e., the diameter of the cylindrical stacks of 3a, was calculated to be $29.8 \AA$ A. The diameter determined by XRD agrees with that obtained from fluorescence anisotropy, which demonstrates that 3a stacks into cylindrical assemblies in both solution and the solid state. Moreover, a prominent peak at $3.66 \AA$, typical of $\pi-\pi$ stacking, is observed. This peak can be attributed to the interplanar reflection between macrocyclic backbones within a column. Applying Scherrer's equation ${ }^{28}$ to this $3.66 \AA$ reflection leads to a correlation length of $22 \mathrm{~nm}$ that corresponds to $\sim 60$ continuously stacked macrocyclic units, which demonstrates the remarkable long-range ordering of the macrocycles within a column.

\section{Transmembrane transport of proton $\left(\mathrm{H}^{+}\right)$}

The tubular assembly of 3, with a non-deformable hydrophilic internal pore of $\sim 8 \AA$ across, could serve as transmembrane
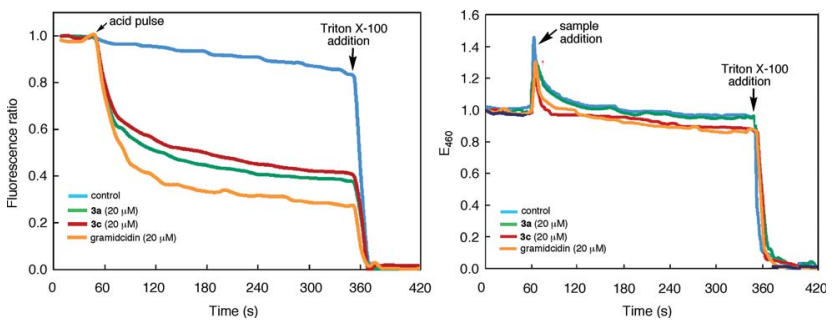

Fig. 6 (a) Time-dependent changes in the (a) ratio of the emission intensities of 8-hydroxypyrene-1,3,6-trisulfonate (HPTS, $0.1 \mathrm{mM}$ ) encapsulated inside large unilamellar vesicles (LUVs) of 1-palmitoyl-2oleoyl-sn-glycero-3-phosphocholine (POPC). Solutions of LUVS (KCl 145 mM, HEPES 100 mM, pH 7.0) were first mixed with 3a, 3c, gramicidin (added from $1 \mathrm{mM}$ stock solutions in THF), or THF (control) and then incubated for $2 \mathrm{~min}$, followed by a $\mathrm{HCl}(2 \mathrm{M})$ pulse. The ratio of emission intensities at $510 \mathrm{~nm}$ by exciting at $450 \mathrm{~nm}$ and $405 \mathrm{~nm}$ respectively was monitored over $5 \mathrm{~min}$; (b) the fluorescence intensity of $N$-(ethoxycarbonylmethyl)-6-methoxyquinolinium bromide (MQAE) encapsulated inside LUVs of POPC. Solutions of $\mathrm{Cl}^{-}$free LUVs (10 mM MQAE, potassium gluconate 100 mM, HEPES 100 mM, pH 7.4) were first incubated with $\mathrm{KCl}(100 \mathrm{mM})$ in HEPES $(100 \mathrm{mM}, \mathrm{pH}$ 7.4) buffer for $1 \mathrm{~min}$. Stock solutions of 3a, 3c, gramicidin ( $1 \mathrm{mM}$ in THF) and THF (control) were added to monitor the change of emission intensity at $460 \mathrm{~nm}\left(\lambda_{\mathrm{ex}}=354 \mathrm{~nm}\right)$ for $5 \mathrm{~min}$. The LUVs were ruptured by adding $200 \mu(\mathrm{L}$ of $1 \times \mathrm{X}$ lysis buffer (1.55 mM Triton X-100 in pH 7.0 Tris-EDTA) (for (a)) or $200 \mu\left(\mathrm{L}\right.$ of Triton X-100 (3.1 mM in $\mathrm{H}_{2} \mathrm{O}$ ) (for (b)). 
channels when partitioning into lipid bilayers. Thus, a solution of large unilamellar vesicles (LUVs) enclosing the $\mathrm{pH}$-sensitive dye HPTS was mixed with 3a and then subjected to an extravesicular acid $(\mathrm{HCl})$ pulse. As shown in Fig. 6a, the decrease of fluorescence emission from the entrapped HPTS in the presence of $\mathbf{3 a}$ is similar to that caused by gramicidin, a well-known channel-forming peptide and is much faster than that of the control. Rupture of the LUVs upon adding Triton X-100, a nonionic surfactant, led to the nearly complete reduction of fluorescence emission. Under the same condition, macrocycle 3c also led to the same reduction of fluorescence emission, suggesting that the observed increase in proton influx was mediated by the inner pores, rather than the side chains, of the tubular assembly.

The transport of anions, or the lack of which, through the nanopores of 3a or 3c was assessed by using LUVs enclosing MQAE, a chloride-sensitive fluorescence dye. ${ }^{29}$ It was found that, in the presence of a chloride gradient across the lipid bilayer, adding $\mathbf{3 a}, \mathbf{3 c}$ or gramicidin failed to quench the fluorescence emission from the entrapped MQAE (Fig. 6b). As expected, rupturing the LUVs with Triton X-100 led to complete quenching of fluorescence emission from MQAE. These results demonstrate that the self-assembling pores of $\mathbf{3}$, with numerous inward pointing amide oxygens, and thus being electrostatically negative, facilitated the transport of cations while impeded the passage of anions.

\section{Conclusions}

Our study shows that the self-assembly of macrocycles 3 is remarkably strong, which affords a robust nanotubular motif that persists in both solution and the solid state. With their sub$\mathrm{nm}$ inner pores, the tubular assemblies of 3 should be of wide use in constructing various nanostructures. For example, with their high stability and tunable solvent-compatibility (by adjusting side chains), the tubular stacks of 3 bode well for developing various mass-transporting channels when partitioned into biological membranes, as exemplified by the cationtransporting capabilities of $\mathbf{3 a}$ and $\mathbf{3 c}$. The persistent nanotubular assemblies of $\mathbf{3}$ may also serve as a reliable supramolecular motif for fabricating nanoporous membranes, e.g., by blending with synthetic polymers. The high propensity of the tubular assemblies of $\mathbf{3}$ for parallel packing may lead to the next-generation membranes consisting of densely packed sub$\mathrm{nm}$ pores. Furthermore, methods adopted in this study should be of general value for analysing hierarchical processes of other self-assembling systems, especially those involving extended or infinite stacks, which remains a major challenge.

\section{Acknowledgements}

We thank the support of the National Science Foundation (CHE1306326) and the Natural Science Foundation of China (91227109). Use of the Advanced Photon Source was supported by the US Department of Energy, Office of Science, Office of Basic Energy Sciences, under contract no. DE-AC02-06CH11357.

\section{Notes and references}

1 (a) U. Koert, Phys. Chem. Chem. Phys., 2005, 7, 1502; (b) H. Bayley and P. S. Cremer, Nature, 2001, 413, 226; (c) N. Sakai, J. Mareda and S. Matile, Acc. Chem. Res., 2008, 41, 1354; (d) W. S. Childers, R. Ni, A. K. Mehta and D. G. Lynn, Curr. Opin. Chem. Biol., 2009, 13, 652.

2 (a) A. Harada, J. Li and M. Kamachi, Nature, 1993, 364, 516; (b) J. M. Schnur, Science, 1993, 262, 1669; (c) N. Sakai, N. Majumdar and S. Matile, J. Am. Chem. Soc., 1999, 121, 4294; (d) S. Tashiro, M. Tominaga, T. Kusukawa, M. Kawano, S. Sakamoto, K. Yamaguchi and M. Fujita, Angew. Chem., Int. Ed., 2003, 42, 3267; (e) V. Percec, A. E. Dulcey, V. S. K. Balagurusamy, Y. Miura, J. Smidrkal, M. Peterca, S. Nummelin, U. Edlund, S. D. Hudson, P. A. Heiney, D. A. Hu, S. N. Magonov and S. A. Vinogradov, Nature, 2004, 430, 764.

3 A. Alexiadis and S. Kassinos, Chem. Rev., 2008, 108, 5014.

4 (a) G. Hummer, J. C. Rasaiah and J. P. Noworyta, Nature, 2001, 414, 188; (b) K. Koga, G. T. Gao, H. Tanaka and X. C. Zeng, Nature, 2001, 412, 802; (c) J. K. Holt, H. G. Park, Y. M. Wang, M. Stadermann, A. B. Artyukhin, C. P. Grigoropoulos, A. Noy and O. Bakajin, Science, 2006, 312, 1034; (d) C. Y. Lee, W. J. Choi, J. H. Han and M. S. Strano, Science, 2010, 329, 1320.

5 (a) D. T. Bong, T. D. Clark, J. R. Granja and M. R. Ghadiri, Angew. Chem., Int. Ed., 2001, 40, 988; (b) D. L. Gin, W. Q. Gu, B. A. Pindzola and W. J. Zhou, Acc. Chem. Res., 2001, 34, 973; (c) N. Sakai and S. Matile, Chem. Commun., 2003, 2514; (d) H. M. Keizer and R. P. Sijbesma, Chem. Soc. Rev., 2005, 34, 226; (e) M. A. B. Block, C. Kaiser, A. Khan and S. Hecht, Top. Curr. Chem., 2005, 245, 89; (f) D. Pasini and M. Ricci, Curr. Org. Synth., 2007, 4, 59; $(g)$ B. Gong and Z. F. Shao, Acc. Chem. Res., 2013, 46, 2856.

6 (a) M. J. Mio, R. B. Prince and J. S. Moore, J. Am. Chem. Soc., 2000, 122, 6134; (b) H. Fenniri, B. L. Deng, A. E. Ribbe, K. Hallenga, J. Jacob and P. Thiyagarajan, Proc. Natl. Acad. Sci. U. S. A., 2002, 99, 6487; (c) Y. Kim, M. F. Mayer and S. C. Zimmerman, Angew. Chem., Int. Ed., 2003, 42, 1121; (d) P. Jonkheijm, A. Miura, M. Zdanowska, F. J. M. Hoeben, S. De Feyter, A. P. H. J. Schenning, F. C. De Schryver and E. W. Meijer, Angew. Chem., Int. Ed., 2004, 43, 74; (e) Z. Q. Hua and C. F. Chen, Chem. Commun., 2005, 2445; $(f)$ M. J. Zhou, P. R. Nemade, X. Y. Lu, X. H. Zeng, E. S. Hatakeyama, R. D. Noble and D. L. Gin, J. Am. Chem. Soc., 2007, 129, 9574; (g) G. D. Pantos, P. Pengo and J. K. M. Sanders, Angew. Chem., Int. Ed., 2007, 46, 194.

7 (a) M. R. Ghadiri, J. R. Granja, R. A. Milligan, D. E. McRee and N. Khazanovich, Nature, 1993, 366, 324; (b) D. Seebach, J. L. Matthews, A. Meden, T. Wessels, C. Baerlocher and L. B. McCusker, Helv. Chim. Acta, 1997, 80, 173; (c) G. Gattuso, S. Menzer, S. A. Nepogodiev, J. F. Stoddart and D. J. Williams, Angew. Chem., Int. Ed., 1997, 36, 1451; (d) O. Y. Mindyuk, M. R. Stetzer, P. A. Heiney, J. C. Nelson and J. S. Moore, Adv. Mater., 1998, 10, 1363; (e) H. Shimura, M. Yoshio and T. Kato, Org. 
Biomol. Chem., 2009, 7, 3205; (f) M. Fritzsche, A. Bohle, D. Dudenko, U. Baumeister, D. Sebastiani, G. Richardt, H. W. Spiess, M. R. Hansen and S. Höger, Angew. Chem., Int. Ed., 2011, 50, 3030; $(g)$ J. K. H. Hui, J. Jiang and M. J. MacLachlan, Can. J. Chem., 2012, 90, 1056; (h) T. Hjelmgaard, O. Roy, L. Nauton, M. El-Ghozzi, D. Avignant, C. Didierjean, C. Taillefumier and S. Faure, Chem. Commun., 2014, 50, 3564.

8 X. B. Zhou, G. D. Liu, K. Yamato, Y. Shen, R. X. Cheng, X. X. Wei, W. L. Bai, Y. Gao, H. Li, Y. Liu, F. T. Liu, D. M. Czajkowsky, J. F. Wang, M. J. Dabney, Z. H. Cai, J. Hu, F. V. Bright, L. He, X. C. Zeng, Z. F. Shao and B. Gong, Nat. Commun., 2012, 3, 949, DOI: 10.1038/ ncomms1949.

9 (a) J. S. Moore, Acc. Chem. Res., 1997, 30, 402; (b) U. H. F. Bunz, Y. Rubin and Y. Tobe, Chem. Soc. Rev., 1999, 28, 107; (c) C. Grave and A. D. Schlüter, Eur. J. Org. Chem., 2002, 67, 3075; (d) Y. Yamaguchi and Z.-I. Yoshida, Chem. Eur. J., 2003, 9, 5430; (e) S. Höger, Chem. - Eur. J., 2004, 10, 1320.

10 (a) J. S. Moore and J. Zhang, Angew. Chem., Int. Ed., 1992, 31, 922; (b) J. Zhang, D. J. Pesak, J. L. Ludwick and J. S. Moore, J. Am. Chem. Soc., 1994, 116, 4227; (c) S. Höger and V. Enkelmann, Angew. Chem., Int. Ed., 1995, 34, 2713; (d) V. Hensel, K. Lutzow, A.-D. Schlüter, J. Jacob, K. Gessler and W. Saenger, Angew. Chem., Int. Ed., 1997, 36, 2654; (e) S. Höger, K. Bonrad, A. Mourran, U. Beginn and M. Moller, J. Am. Chem. Soc., 2001, 123, 5651; (f) K. Nakao, M. Nishimura, T. Tamachi, Y. Kuwatani, H. Miyasaka, T. Nishinaga and M. Iyoda, J. Am. Chem. Soc., 2006, 128, 16740; (g) S. H. Seo, T. V. Jones, H. Seyler, J. O. Peters, T. H. Kim, J. Y. Chang and G. N. Tew, J. Am. Chem. Soc., 2006, 128, 9264; (h) S. W. Sisco and J. S. Moore, J. Am. Chem. Soc., 2012, 134, 9114; (i) F. Schlütter, F. Rossel, M. Kivala, V. Enkelmann, J.-P. Gisselbrecht, P. Ruffieux, R. Fasel and K. Müllen, J. Am. Chem. Soc., 2013, 135, 4550; (j) A. V. Aggarwal, A. Thiessen, A. Idelson, D. Kalle, D. Würsch, T. Stangl, F. Steiner, S.-S. Jester, J. Vogelsang, S. Höger and J. M. Lupton, Nat. Chem., 2013, 5, 964.

11 Examples of macrocyclic aromatic oligoureas: (a) F. Böhme, C. Kunert, H. Komber, D. Voigt, P. Friedel, M. Khodja and H. Wilde, Macromolecules, 2002, 35, 4233; (b) L. Xing, U. Ziener, T. C. Sutherland and L. A. Cuccia, Chem. Commun., 2005, 5751; (c) A. Zhang, Y. Han, K. Yamato, X. C. Zeng and B. Gong, Org. Lett., 2006, 8, 803; (d) A. Gube, H. Komber, K. Sahre, P. Friedel, B. Voit and F. Böhme, J. Org. Chem., 2012, 77, 9620; (e) Z. Wu, T. Hu, L. He and B. Gong, Org. Lett., 2012, 14, 2504.

12 Example of macrocyclic aromatic oligo(imines): P. D. Frischmann, G. A. Facey, P. Y. Ghi, A. J. Gallant, D. L. Bryce, F. Lelj and M. J. MacLachlan, J. Am. Chem. Soc., 2010, 132, 3893.

13 Examples of macrocyclic aromatic oligosulfonamides: (a)

L. He, Y. An, L. Yuan, K. Yamato, W. Feng, O. Gerlitz, C. Zheng and B. Gong, Chem. Commun., 2005, 3788; (b) L. He, Y. An, L. Yuan, W. Feng, M. Li, D. Zhang,
K. Yamato, C. Zheng, X. C. Zeng and B. Gong, Proc. Natl. Acad. Sci. U. S. A., 2006, 103, 10850.

14 Examples of macrocyclic aromatic oligoamides: (a) L. H. Yuan, W. Feng, K. Yamato, A. R. Sanford, D. G. Xu, H. Guo and B. Gong, J. Am. Chem. Soc., 2004, 126, 11120; (b) H. Jiang, J.-M. Léger, P. Guionneau and I. Huc, Org. Lett., 2004, 6, 2985; (c) F. Campbell, J. Plante, C. Carruthers, M. J. Hardie, T. J. Prior and A. J. Wilson, Chem. Commun., 2007, 2240; (d) B. Qin, C. Ren, R. Ye, C. Sun, K. Chiad, X. Chen, Z. Li, F. Xue, H. Su, G. A. Chass and H. Zeng, J. Am. Chem. Soc., 2010, 132, 9564.

15 Examples of other rigid macrocycles: (a) J. L. Sessler, E. Tomat and V. M. Lynch, Chem. Commun., 2006, 4486; (b) K. Nakao, M. Nishimura, T. Tamachi, Y. Kuwatani, H. Miyasaka, T. Nishinaga and M. Iyoda, J. Am. Chem. Soc., 2006, 128, 16740; (c) J. M. Holub, H. J. Jang and K. Kirshenbaum, Org. Lett., 2007, 9, 3275; (d) Y. Li and A. H. Flood, Angew. Chem., Int. Ed., 2008, 47, 2649; (e) S. Lee, C.-H. Chen and A. H. Flood, Nat. Chem., 2013, 5, 704. 16 K. Yamato, M. Kline and B. Gong, Chem. Commun., 2012, 48, 12142.

17 A. R. Sanford and B. Gong, Curr. Org. Chem., 2003, 7, 1649. 18 (a) L. H. Yuan, H. Q. Zeng, K. Yamato, A. R. Sanford, W. Feng, H. Atreya, D. K. Sukumaran, T. Szyperski and B. Gong, J. Am. Chem. Soc., 2004, 126, 16528; (b) L. H. Yuan, A. R. Sanford, W. Feng, A. M. Zhang, J. S. Ferguson, K. Yamato, J. Zhu, H. Q. Zeng and B. Gong, J. Org. Chem., 2005, 70, 10660.

19 J. X. Cao, M. Kline, Z. Z. Chen, B. Luan, M. L. Lv, W. Zhang, C. X. Lian, Q. W. Wang, Q. F. Huang, X. X. Wei, J. G. Deng, J. Zhu and B. Gong, Chem. Commun., 2012, 48, 11112.

20 (a) W. Feng, K. Yamato, L. Q. Yang, J. Ferguson, L. J. Zhong, S. L. Zou, L. H. Yuan, X. C. Zeng and B. Gong, J. Am. Chem. Soc., 2009, 131, 2629; (b) J. S. Ferguson, K. Yamato, R. Liu, L. He, X. C. Zeng and B. Gong, Angew. Chem., Int. Ed., 2009, 48, 3150.

21 (a) R. D. Parra, H. Q. Zeng, J. Zhu, C. Zheng, X. C. Zeng and B. Gong, Chem. - Eur. J., 2001, 7, 4352; (b) R. D. Parra, M. Furukawa, B. Gong and X. C. Zeng, J. Chem. Phys., 2001, 115, 6030; (c) R. D. Parra, B. Gong and X. C. Zeng, J. Chem. Phys., 2001, 115, 6036.

22 Y. A. Yang, W. Feng, J. C. Hu, S. L. Zou, R. Z. Gao, K. Yamato, M. Kline, Z. H. Cai, Y. Gao, Y. B. Wang, Y. B. Li, Y. L. Yang, L. H. Yuan, X. C. Zeng and B. Gong, J. Am. Chem. Soc., 2011, 133, 18590.

23 X. X. Wu, G. X. Liang, G. Ji, H. K. Fun, L. He and B. Gong, Chem. Commun., 2012, 48, 2228.

24 M. Kline, X. X. Wei and B. Gong, Org. Lett., 2013, 15, 4762.

25 J. B. Birk, Photophysics of Aromatic Molecules, WileyInterscience, New York, 1970.

26 (a) J. K. Rice, E. D. Niemeyer, R. A. Dunbar and F. V. Bright, J. Am. Chem. Soc., 1995, 117, 5832; (b) R. B. Prince, J. G. Saven, P. G. Wolynes and J. S. Moore, J. Am. Chem. Soc., 1999, 121, 3114.

27 S. Kumar, Chem. Soc. Rev., 2006, 35, 83.

28 B. D. Cullity and S. R. Stock, Elements of X-Ray Diffraction, Prentice-Hall, New Jersey, 3rd edn, 2001.

29 A. S. Verkman, Am. J. Physiol., 1990, 259, C375. 